\title{
Experimental comparison between traditional and cryogenic cooling conditions in rough turning of Ti-6Al-4V
}

\author{
Stefano Tirelli ${ }^{1, a}$, Elio Chiappini ${ }^{1, b}$, Matteo Strano ${ }^{2, c}$, Michele Monno ${ }^{2, d}$, Quirico \\ Semeraro $2, e$ \\ ${ }^{1}$ Laboratory Macchine Utensili e Sistemi di Produzione, MUSP, via Tirotti 9, Piacenza, Italy \\ ${ }^{2}$ Dipartimento di Meccanica, Politecnico di Milano, via La Masa 1, I-20156 Milano, Italy \\ astefano.tirelli@musp.it, ${ }^{b}$ elio.chiappini@musp.it, \\ ${ }^{c}$ matteo.strano@polimi.it, ${ }^{d}$ michele.monno@polimi.it, ${ }^{e}$ quirico.semeraro@polimi.it
}

Keywords: Ti6Al4V, titanium alloys, turning, emulsion cooling, cryogenic cooling, tool wear, insert

\begin{abstract}
Titanium alloys, mainly because of their poor thermal conductivity, need to be cut at relatively low cutting speeds to avoid a severe diffusion wear, with obvious negative consequences on the profitability of machining. An important amount of research activities has been done in order to increase productivity in titanium machining operations and one of the most promising solutions is represented by the use of liquid nitrogen as a coolant during the machining operation.

The aim of this paper is to compare traditional and cryogenic turning of Ti6Al4V in a region of cutting parameters particularly relevant to the aerospace industry where no previous data are available. The cutting parameters are those typical of titanium alloys rough machining which is considered, cost-wise, the most important operation because, for aerospace components, the socalled Buy-To-Fly ratio can reach values up to $20: 1$.

The experiments have been performed using a full factorial design in order to statistically evaluate, using ANOVA and regression analyses, the significance of the input factors on the process most interesting outputs. The considered input factors are: type of cooling method, cutting speed and feed rate. The main analysed responses are: tool wear, surface roughness, cutting forces, coefficient of friction and chip morphology.

The results show the significance of the cooling method on the tool life and that cryogenic machining is able to increase the tool life with respect to wet cutting. On the other hand, the beneficial effect of the liquid nitrogen cooling is reduced at high cutting speed and feed rate. Besides, the results showed that a small but significant reduction can be achieved for both the repulsion force and the coefficient of friction at the tool-workpiece interface,
\end{abstract}

\section{Introduction and state of the art}

Titanium alloys present many interesting mechanical properties (such as very high strength to weight ratio, high toughness, biocompatibility and good corrosion resistance) that promote the use of these materials not only in the aerospace industry, but also for bio-medical applications and for the chemical and oil \& gas industries. Conversely, titanium alloys are classified as "difficult to machine" materials especially due to their low thermal conductivity, which is one of the most important material characteristics when considering machinability [1]. Furthermore, titanium shows low elastic modulus and high chemical reactivity [2]. Among several problems encountered in titanium machining, the quick tool failure due to an excessive wear represents one of the most critical issues.

High cutting performance is strongly needed in aerospace manufacturing, where generally rough machining removes about $90 \%$ of the material from the blank, even in small parts production. This manufacturing approach is typically adopted due to the high costs of titanium forgings and to the fact that dedicated dies are not economically feasible, because of small production batches. So far, a lot of research has been done to study and to improve the performance of carbide tools in titanium 
machining. The use of cryogenic cooling in metal cutting has received renewed recent attention because liquid nitrogen $\left(\mathrm{LN}_{2}\right)$ is a safe, clean, non-toxic coolant that requires no expensive disposal and can substantially improve tool life.

Uehara and Kumagai [3] have pioneered works on cryogenics in machining. A relatively recent review of cryogenics in machining has been written by Yildiz and Nalbant [4]. Cryogenic cooling approaches in machining can be classified into several types according to the delivery method [5]: pre-cooling of the workpiece, tool back cooling, tool flank cooling, tool rake cooling and simultaneous rake and flank cooling. The most effective cooling approaches are the last two: rake only cooling or flank and rake cooling. All studies agree that these cooling techniques reduce the tool temperature and prolong its life, with respect to dry cutting and to conventional emulsion lubrication. Recent studies by Bermingham and co-workers demonstrate that using high pressure emulsion lubrication outperforms cryogenic cooling with respect to tool life [6]; in both cases the nozzle design is critical for a successful operation. It is reasonable to expect that the advantage of cryogenic cooling vs. water based oil emulsion lubrication with respect to tool life enhancement should depend on the selected levels for the process parameters (feed rate, depth of cut, cutting speed). The role of cutting speed and other parameters in cryogenic cutting of titanium alloys is not yet unanimously assessed. Some authors observed that the greatest improvement in tool life using cryogenic coolant occurs for high feed rate and low depth of cut combinations [7], with constant cutting speed and approximately constant MRR. The authors also proved that these conditions do not represent the optimal operating parameters with respect to economic efficiency nor they allow to maximize the tool life. Some authors have proved that, in machining of AISI 304 stainless steel [8] or of titanium [9], the percentage tool life advantage and the economic convenience of cooling by liquid nitrogen, with respect to conventional emulsion lubrication, increases as the cutting speed increases. According to other studies, the advantage of cryogenics is nearly independent on the process parameters, at least for stainless steel [10]. On the contrary, some claim that with the increase in cutting speed to very high levels (up to $100 \mathrm{~m} / \mathrm{min}$ and above), the differences tend to decrease, in terms of wear on the rake face of the tool [11].

Similar contrasting results emerge from the literature when forces and friction coefficient are analysed. Results of cutting force measurements often indicate that the cold strengthening of titanium material might increase the cutting force in cryogenic machining, but lower friction allows to reduce the feed force, compared to dry cutting [12]. Although many authors compare the performance of liquid nitrogen vs. dry cutting condition [13][14], a more meaningful comparison of forces and friction should be done with respect to conventional emulsion lubrication. As anticipated, not all studies in the literature agree. Some works demonstrate that no change in the cutting forces [15] occurs. Other studies report a decrease in both main cutting and feed forces for cryogenic vs. wet conditions, regardless of cutting speed [16]. As for the tool life, it is reasonable to expect that the advantage of cryogenic cooling compared to the more widespread emulsion lubrication with respect to forces (cutting, feed and repulsion forces) depends on process parameters values. In fact, recent research works prove that force reduction is greatest when using high feed rate and low depth of cut combinations [7], if keeping constant the cutting speed. An increase in cutting speed, according to most previous works, causes also a decrement of the coefficient of friction for dry, water-oil emulsion based cooling and cryogenic cooling [17][18].

The differences between conventional and cryogenic machining may be due to several causes: both tool and workpiece can be hardened by the low working temperatures, the tribological conditions are altered, etc. As a consequence, cryogenic machining changes the mechanics of the chip formation, generating a thinner [7] and more discontinuous [19] chip and also a limited amount of built up edge [17] if compared to dry machining.

A recent work by Rotella et al. [20] showed the capability of cryogenic cooling to improve the product surface finishing, in terms of surface roughness, microhardness and grain size, with respect to dry and MQL turning of Ti6Al4V alloy.

In conclusion, all authors agree that cryogenic cooling allows a significant improvement of the tool life over dry machining. When compared to traditional flood cooling, less results are available, but 
all results agree that cryogenics has a great potential of improving the process performance. However, especially when the process is compared to standard industrial cutting conditions, different researchers have obtained conflicting results. One possible explanation for these differences is that the design of the injection system strongly influences the process, as it determines the localization of the nitrogen flow on the workpiece-tool interface surfaces and the flow rate guaranteed by the overall cryogenic injection systems. It is worth observing that, due to inherent difficulties in measuring the actual flow rate of the coolant, it is very difficult if not impossible to find data about this supposedly important parameter. Another source of variation among different results is that the investigated range of process parameters varies from paper to paper. In order for the coolant to have time enough to subtract heat from the working area, it seems reasonable that the influence of nitrogen, which is injected through small nozzles, is larger for smaller values of MRR. On the other hand, it also seems reasonable that the advantage of cryogenics in terms of tool life becomes evident only at larger cutting speeds, i.e. when the tool is more stressed by higher cutting forces and higher heat generation. The expected outcome of the process is therefore not so trivial and the results can easily be influenced by the cutting conditions. There is a need for additional experimental evidence with respect to different issues, such as the three components of force (cutting, feed and thrust), the coefficient of friction, the rate of tool wear at different values of the process parameters.

Rough turning is economically more relevant to the machining industry, especially in the aerospace field where the so-called buy-to-fly ratio can be as large as 10:1 and above [21]. Because of their poor machinability, titanium alloys are industrially cut with moderate cutting parameters. In rough turning, in order to avoid premature tool failure, cutting speed vc and feed rate $f$ are never set respectively above $60 \mathrm{~m} / \mathrm{min}$ and $0.4 \mathrm{~mm} / \mathrm{rev}$.

Besides, in order for the industry to evaluate the actual advantage of cryogenic coolants, the performance must be compared to conventional flood emulsion cooling, not to dry conditions, which are never used industrially. No paper in this literature review investigates the cutting forces at low speed and high feed and only two papers [15][16] report force comparisons with respect to emulsion cooling. In this paper, some new experimental observations are presented, in order to fill this gap, providing cutting force measurements with emulsion and cryogenic cooling, at a relatively low cutting speed $(50 \mathrm{~m} / \mathrm{min})$ and a relatively high feed rate $(0.3 \mathrm{~mm} / \mathrm{rev})$.

The main goal of this paper is to fill some gaps that have been identified in the scientific literature and underlined above and to compare the effect of emulsion cooling and liquid nitrogen cooling, within an industrially relevant range of working parameters, on tool life and other important process parameters.

The paper is organised as follows: the detailed description of tool, inserts, cryogenic adduction scheme, experimental setup and procedure is presented in Section 2. The results and discussion of the experimentations are proposed in Section 3, focusing on tool flank wear progression, cutting forces and tribological aspects. Finally, in Section 4 some conclusions are drawn.

\section{Lathe Turning Tests}

Experimental setup. The workpiece consisted in Ti6Al4V bars with $55 \mathrm{~mm}$ as initial diameter. The certificate of the adopted material, provided by the seller, reports a tensile strength of $934 \mathrm{MPa}$ and a yield strength of $867 \mathrm{MPa}$. The effect of the microstructure of titanium alloys on their machinability is relevant, as demonstrated by several authors [22][23]. The material microstructure has been analysed along the bar diameter and it can be considered quite homogeneous, according to a micrographic that shows a substantially uniform granularity across the cross section of the bars.

All machining trials have been conducted using a CNC Somab Unimab 400 lathe with a maximum spindle speed of $2560 \mathrm{rev} / \mathrm{min}$ and a drive motor rated up to $11 \mathrm{~kW}$.

The machining trials were aimed at comparing the difference in terms of tool life between traditional and cryogenic cooling method. Traditional fluid is a water-oil emulsion (Hocut 795/I) at a concentration of 5\% and a flow rate of $21 / \mathrm{min}$. The cryogenic system consisted in a dewar (courtesy of SIAD, Fig. ${ }^{\circ}$ ) at a pressure of $160 \mathrm{kPa}$ with a capacity of 2401 and a thermally 
insulated metal pipe that delivers the fluid to a commercial tool holder MIRCONA PCLNL 2525 EB, Fig. ${ }^{\circ}$ ). The tool holder has two injection nozzles for both rake and flank cooling.

The insert type used during the turning test is a commercial Sandvik CNMG 120408 SMR 1115, well suited for rough turning of titanium alloys. The insert is a coated carbide tool with coating layers TiAlN $(2 \mu \mathrm{m})+\mathrm{AlCrO}(0.7 \mu \mathrm{m})$. Hardness measurements of the insert have been performed with a pressing load of $0.5 \mathrm{~kg}$, selected in order to characterize the hardness of the entire tool: WC + coating layers. Each hardness value has been computed considering six repeated hardness measurements on the tool flank. The insert presented a mean surface hardness of $1878 \mathrm{HV}$.
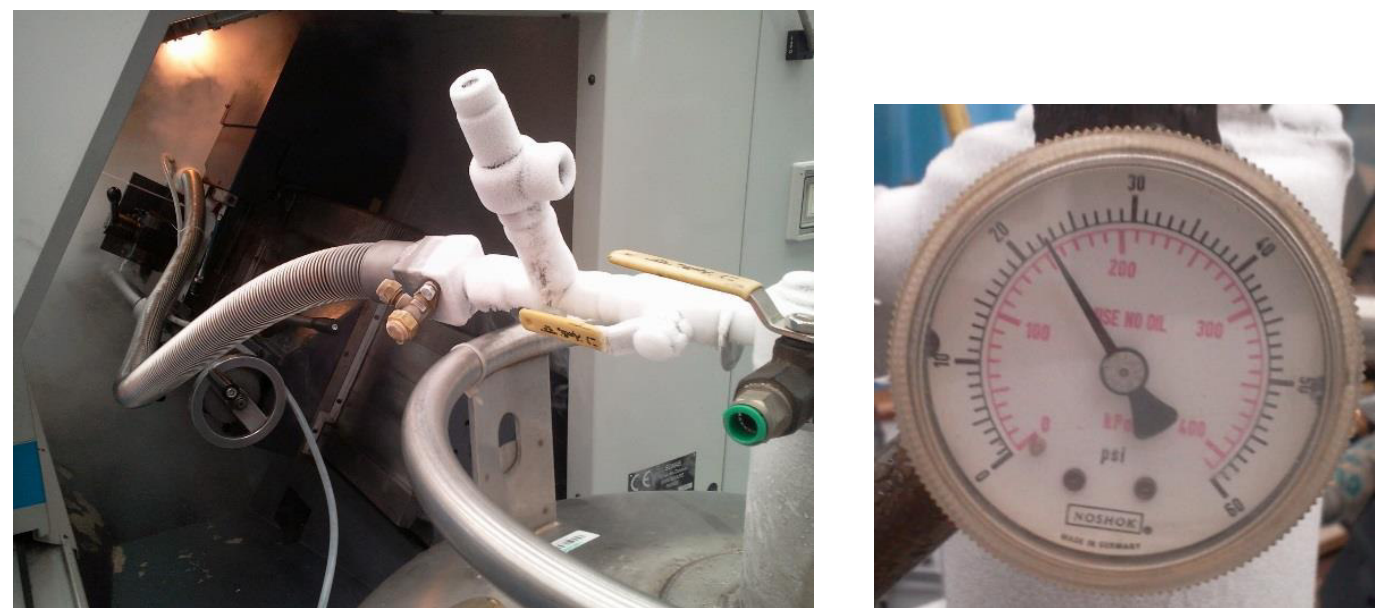

Fig. ${ }^{\circ}$ : view of the piping connecting the dewar to the lathe; manometer.

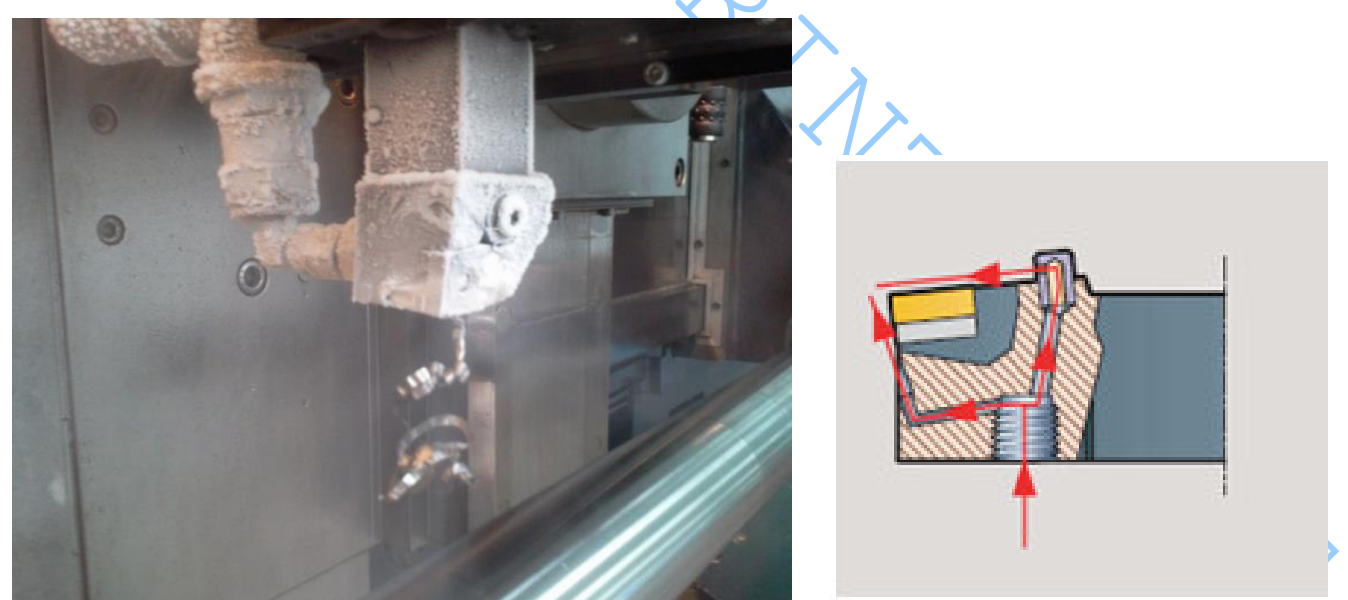

Fig. ${ }^{\circ}$ : view of the cooled toolholder and the titanium bar; scheme of the internal holes of the toolholder.

The cutting tests have been performed with the following parameters: entry angle $\kappa_{\mathrm{r}}=95^{\circ}$, top rake angle $\gamma=-6^{\circ}$, side clearance angle $\alpha=5^{\circ}$, back rake angle $\lambda=-6^{\circ}$. The process parameters are summarized in Table 1.

Experimental plan. An experimental plan has been designed in order to evaluate and compare the influence on tool life and other process parameters of two different cooling methods: water-oil emulsion and cryogenic cooling. The parameters have been selected according to a full factorial Design of Experiments (DOE) with centerpoint [24], with the following input factors: cooling method, cutting speed and feed rate. Their levels are listed in Table 1. Three replicates were performed for every cutting condition. The experimental plan consists of 5 tests $(2$ cutting speeds and 2 feed rates plus one centerpoint) for both cooling types for a total of 30 turning runs. The ANOVA test has been used as the statistical method to determine if each investigated factor significantly affects the measured responses. A I-type error threshold $\alpha=0.01$ has been adopted for every F-test of the ANOVA table. 
Table 1. Machining parameters for turning tests

\begin{tabular}{|l|l|}
\hline Factors & Levels \\
\hline Cutting speeds $\left(\mathrm{V}_{\mathrm{c}}\right)$ & 50,60 (center point) and $70[\mathrm{~m} / \mathrm{min}]$ \\
\hline Feed rates $(\mathrm{f})$ & $0.2,0.25($ center point) and $0.3[\mathrm{~mm} / \mathrm{rev}]$ \\
\hline Depth of cut $(\mathrm{b})$ & $2[\mathrm{~mm}]$ \\
\hline Cutting fluid & $\begin{array}{l}\text { 1) Hocut } 795 / \mathrm{I} \text { at a concentration of } 5 \% \text { and a flow rate of } 2[1 / \mathrm{min}] \\
\text { 2) Liquid nitrogen cooling }\end{array}$ \\
\hline
\end{tabular}

Average flank wear $\mathrm{VB}_{\mathrm{B}}$ was measured on micrographic images, taken using an Optika stereomicroscope; the positioning reproducibility of the measured insert was guaranteed by an adequately designed insert holder, fixed to the base of the microscope. Images have been analysed after being processed, as suggested in [25]. Each test has been interrupted at least five times (according to ISO9685), in order to have six points on the $\mathrm{VB}_{\mathrm{B}}$ vs. time curves. The tool failure adopted criterion is the average flank wear of $0.3 \mathrm{~mm}$.

A Kistler dynamometric table has been used to measure all three orthogonal components of the cutting force: main cutting force $F_{c}$, feed force $F_{f}$, thrust or radial force $F_{r}$.

\section{Results and discussion}

The results are now presented and discussed. ANOVA analyses were performed to determine the influence of the experimental plan parameters, with particular focus on the cooling method, on the response variables. The considered variables are: tool wear, surface roughness, cutting forces, coefficient of friction and chip morphology.

Tool life. In Table 2 the average tool life in terms of removed material and cutting time for every cutting parameters combination is reported.

Table 2. Average tool life values for every cutting condition with traditional and cryogenic cooling

\begin{tabular}{|c|c|c|c|c|c|c|c|}
\hline $\begin{array}{c}v c \\
{[\mathrm{~m} / \mathrm{min}]}\end{array}$ & $\begin{array}{c}f \\
{[\mathrm{~mm} / \mathrm{rev}]}\end{array}$ & $\begin{array}{c}a p \\
{[\mathrm{~mm}]}\end{array}$ & $\begin{array}{c}M R R \\
{\left[\mathrm{~mm}^{3} / \mathrm{sec}\right]}\end{array}$ & $\begin{array}{c}V \text { cryo } \\
{\left[\mathrm{mm}^{3}\right]}\end{array}$ & $\begin{array}{c}V \text { wet } \\
{\left[\mathrm{mm}^{3}\right]}\end{array}$ & $\begin{array}{c}T \text { cryo } \\
{[\mathrm{sec}]}\end{array}$ & $\begin{array}{c}T \text { wet } \\
{[\mathrm{sec}]}\end{array}$ \\
\hline 50 & 0.2 & 2 & 333 & 351678 & 292920 & 1055 & 879 \\
\hline 50 & 0.3 & 2 & 500 & 279163 & 284150 & 837 & 852 \\
\hline 60 & 0.25 & 2 & 500 & 232158 & 199547 & 696 & 599 \\
\hline 70 & 0.2 & 2 & 467 & 158892 & 152887 & 477 & 459 \\
\hline 70 & 0.3 & 2 & 700 & 59258 & 54256 & 178 & 163 \\
\hline
\end{tabular}

Cryogenic cooling improves tool life in about all conditions, in particular at $50 \mathrm{~m} / \mathrm{min}$ and 0.2 $\mathrm{mm} / \mathrm{rev}$ (about 20\%) and at $60 \mathrm{~m} / \mathrm{min}$ and $0.25 \mathrm{~mm} / \mathrm{rev}$ (about 16\%). At the other conditions there is a substantial equality of tool life between the two cooling methods. 


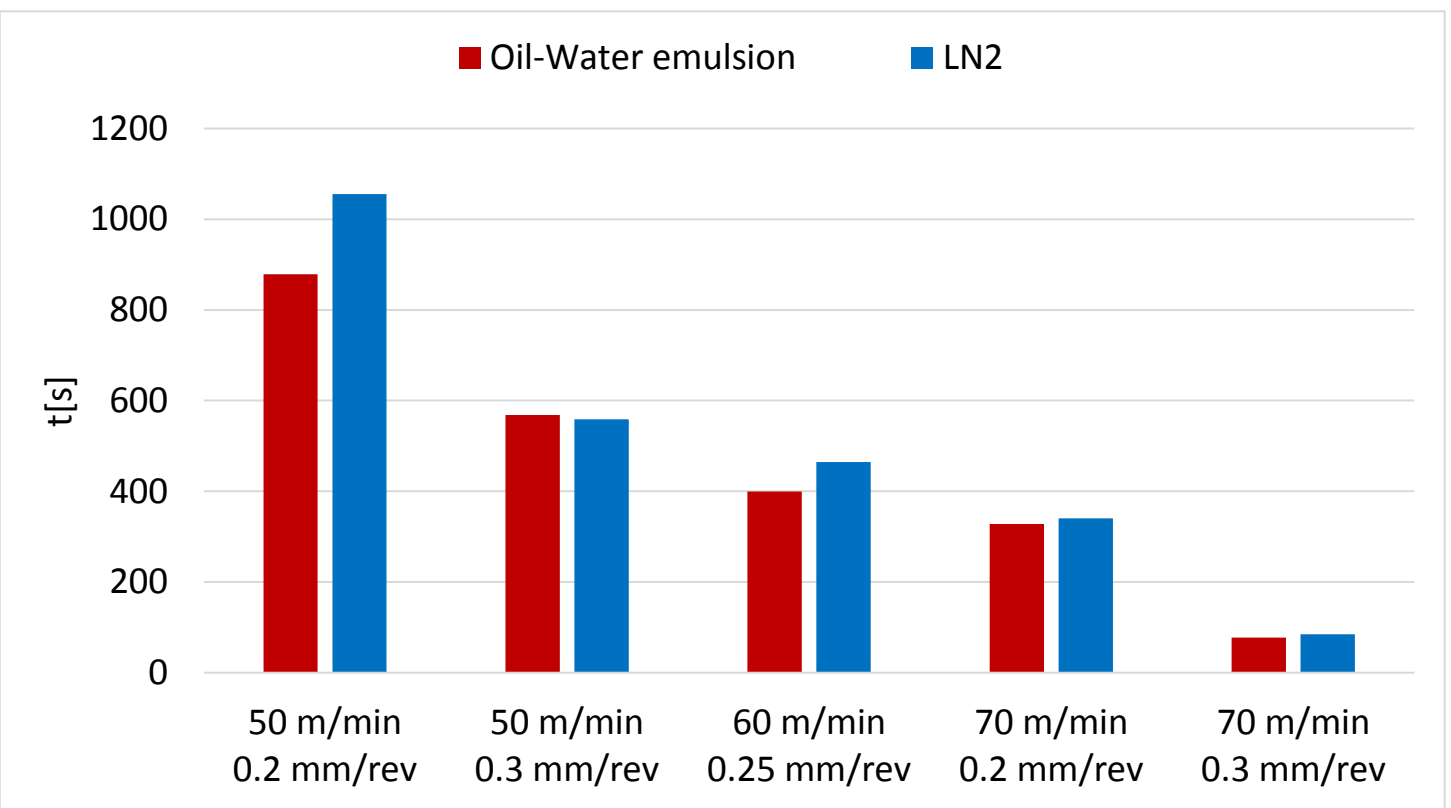

Fig. ${ }^{\circ}$ 3. Average tool life for each cutting condition

At high cutting speed or high feed rate, $\mathrm{LN}_{2}$ seems to decrease its capability of reaching the cutting zone. This can be due to two main factors: 1) the larger amount of generated heat; 2) liquid nitrogen is not highly pressurized inside the dewar and the nozzle is located at about $20 \mathrm{~mm}$ away from the cutting edge. Thus, the $\mathrm{LN}_{2}$ jet speed may not be sufficient to get to the cutting edge in its liquid phase losing a large part of its capability of heat removal.

The obtained results are according with the flooding $\mathrm{LN}_{2}$ adduction tested by Hong et al. [26] which was performed in similar setup conditions with the present work.

Statistical analysis. For the two cooling conditions, two different tool wear models were obtained to predict the flank wear amount basing on cutting parameters and cumulated machining time. For this general regression analysis the progression of tool wear, $V_{B}(\mu \mathrm{m})$, at each stop of all the performed tests was considered as output. A Box-Cox transformation of the response was implemented in order to improve the diagnostics of the regression residuals. The suggested rounded $\lambda$ for the transformation was equal to -1 hence the factors values (cutting speed ' $\mathrm{vc}$ ', feed rate ' $\mathrm{f}$ ', cumulated machining time ' $t$ cum') were transformed adopting the natural logarithm factor.

Traditional emulsion cooling is -1 and cryogenic cooling method value is +1 .

The laws obtained for the two levels of cooling method ('refr') are reported below. All factors and interaction are significant, with the exception of the interaction $\ln (f) * \ln (t$ cum) .

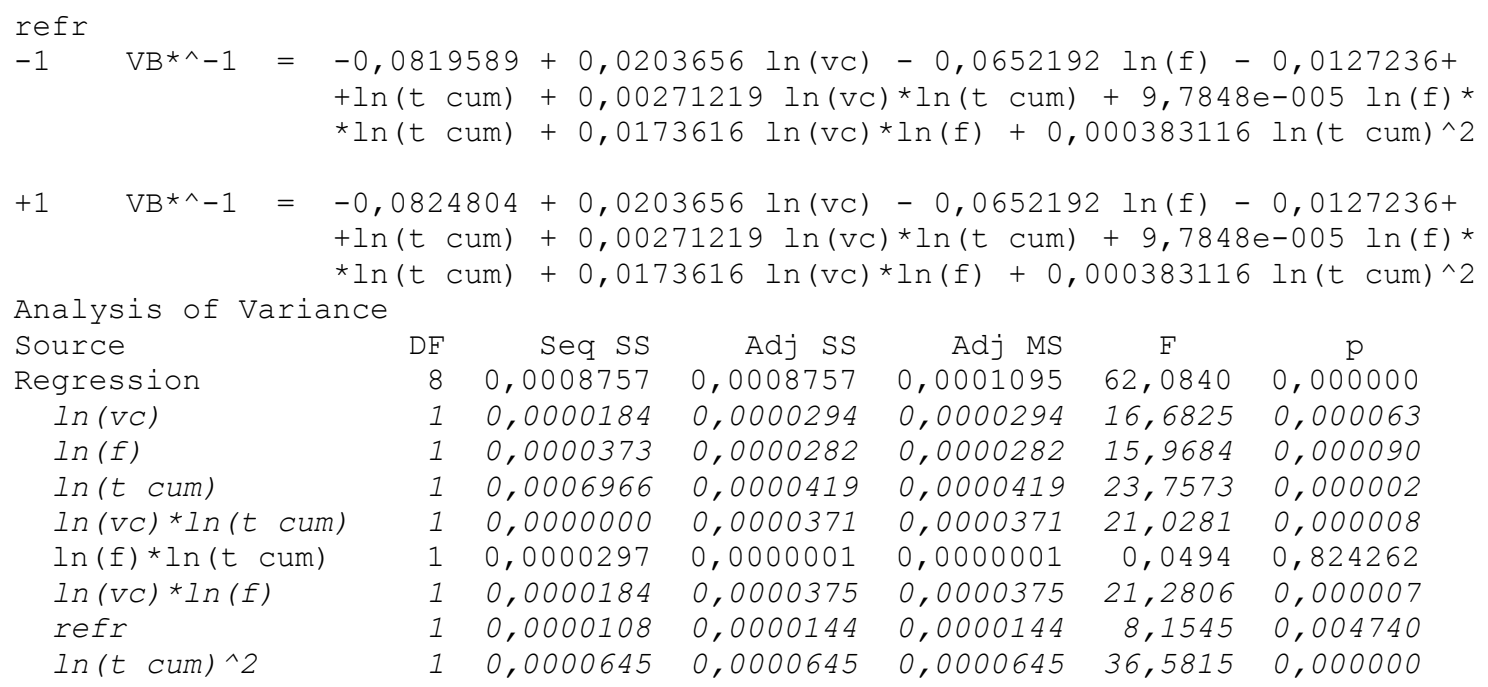

Source

Regression

$\ln (V C)$

$\ln (f)$

$\ln (t$ cum)

$\ln (v C) * \ln (t \quad c u m)$

$\ln (f) * \ln (t \quad c u m)$

$\ln (V C) * \ln (f)$

refr

In $(t \text { cum })^{\wedge} 2$

DF

Seq SS

0,0008757

0,0000184

0,0000373

0,0006966

0,0000000

0,0000297

0,0000184

0,0000108

0,0000645

Adj SS

0,0008757

0,0000294

0,0000282

0,0000419

0,0000371

0,0000001

0,0000375

0,0000144

0,0000645

Adj MS

0,0001095

0,0000294

0,0000282

0,0000419

0,0000371

0,0000001

0,0000375

0,0000144

0,0000645

$\mathrm{F}$

62,0840

16,6825

15,9684

23,7573

21,0281

0,0494

21,2806

8,1545

36,5815

$\mathrm{p}$

0,000000

0,000063

0,000090

0,000002

0,000008

0,824262

0,000007

0,004740

0,000000 
The cooling method ('refr') is a significant factor with a p-value of about 0.005 , hence there is a statistical difference between the two $\mathrm{V}_{\mathrm{B}}$ laws obtained. The only factor that does not influence the flank wear is the interaction between feed rate and machining time.

Cutting forces and chip morphology. Average cutting forces and chip morphology were measured and statistically analysed to understand the influence of the chosen factors, in particular the cooling method, on the cutting mechanics. All the analysed cutting force data are referred to the first passes of each test when the tool wear is negligible, to ignore the typical increase in cutting forces that occurs when the insert is nearing the end of its life. Like the tool wear level, also the cutting forces and chip morphology were statistically analysed using ANOVA tests.

In Table 3 the mean cutting $(\mathrm{Fc})$, feed $(\mathrm{Ff})$ and repulsion $(\mathrm{Fr})$ forces, obtained by averaging the measures among the three replicates, are reported.

Table 3. Mean cutting forces for every cutting condition

\begin{tabular}{|c|l|c|c|c|c|c|}
\multicolumn{2}{l|}{} & $\begin{array}{c}50 \mathrm{~m} / \mathrm{min} \\
0.2 \mathrm{~mm} / \mathrm{rev}\end{array}$ & $\begin{array}{c}50 \mathrm{~m} / \mathrm{min} \\
0.3 \mathrm{~mm} / \mathrm{rev}\end{array}$ & $\begin{array}{c}60 \mathrm{~m} / \mathrm{min} \\
0.25 \mathrm{~mm} / \mathrm{rev}\end{array}$ & $\begin{array}{c}70 \mathrm{~m} / \mathrm{min} \\
0.2 \mathrm{~mm} / \mathrm{rev}\end{array}$ & $\begin{array}{c}70 \mathrm{~m} / \mathrm{min} \\
0.3 \mathrm{~mm} / \mathrm{rev}\end{array}$ \\
\hline \multirow{2}{*}{$\mathrm{Fc}[\mathrm{N}]$} & Emulsion & 818 & 1045 & 894 & 752 & 1051 \\
\cline { 2 - 7 } & Cryo & 806 & 1075 & 884 & 734 & 1084 \\
\hline \multirow{2}{*}{ Ff [N] } & Emulsion & 434 & 403 & 372 & 358 & 460 \\
\cline { 2 - 7 } & Cryo & 381 & 421 & 357 & 344 & 487 \\
\hline \multirow{2}{*}{ Fr $[\mathrm{N}]$} & Emulsion & 230 & 253 & 214 & 196 & 263 \\
\cline { 2 - 7 } & Cryo & 229 & 259 & 246 & 211 & 295 \\
\hline
\end{tabular}

Starting from the main cutting force values the corresponding specific cutting pressure $(\mathrm{Kc})$ was calculated. An ANOVA test showed that Kc is not influenced by the cooling type but the interaction between cooling method and feed rate is found to be influent. This can support the aforementioned hypothesis that at high feed rates the $\mathrm{LN}_{2}$ jet cannot adequately penetrate into the cutting zone and efficiently remove the generated heat.

Feed force is influenced only by the feed rate level and the radial force by both the feed rate and the cooling type. The influence of cooling type on the repulsion force is probably due to the fact that having a colder workpiece causes a slight local increment of hardness thus a major force is required to the tool to penetrate in the workpiece.

In Table 4 the obtained p-values for all the ANOVA tests on the cutting forces are reported; the significant ones are printed in italic font.

Table 4. Obtained p-values for the ANOVA tests

\begin{tabular}{|c|c|c|c|c|}
\hline & \multicolumn{3}{|c|}{ Variable } \\
\hline & & $\mathrm{Kc}$ & $\mathrm{Ff}$ & $\mathrm{Fr}$ \\
\hline \multirow{8}{*}{ 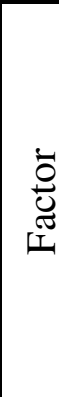 } & $\mathrm{vt}$ & 0 & 0.867 & 0.823 \\
\hline & $f$ & 0 & 0 & 0 \\
\hline & refr & 0.922 & 0.555 & 0.010 \\
\hline & $\mathrm{vt} * \mathrm{f}$ & 0 & 0 & 0.002 \\
\hline & $\mathrm{vt} * \mathrm{refr}$ & 0.911 & 0.383 & 0.133 \\
\hline & f*refr & 0.026 & 0.06 & 0.386 \\
\hline & $\mathrm{vt} * \mathrm{f} * \mathrm{refr}$ & 0.817 & 0.598 & 0.698 \\
\hline & $\mathrm{Ct} \mathrm{Pt}$ & 0.001 & 0.007 & 0.125 \\
\hline
\end{tabular}

All cutting tests produced a serrated chip (Fig. $\left.{ }^{\circ} 4\right)$. Chip dimensions, considering peak and valley height and peak to peak distance, were measured from chip samples collected for every cutting condition. The results are reported in Table 5. An ANOVA analysis showed the influence of feed rate on all the three chip dimensions. Peak to peak distance was also influenced by the cutting speed 
factor. This analysis shows that the cryogenic cooling does not alter chip formation mechanics despite its strong cooling effect. This is also supported by the fact that the main cutting force is not influenced by the $\mathrm{LN}_{2}$ cooling.

Segmentation frequency values range from about $3500 \mathrm{~Hz}$ to $7000 \mathrm{~Hz}$, with cutting speed and feed rate being the significant factors.

Table 5. Average chip morphology for every cutting test condition

\begin{tabular}{|c|l|r|r|r|r|r|}
\cline { 3 - 7 } \multicolumn{2}{l|}{} & $\begin{array}{c}50 \mathrm{~m} / \mathrm{min} \\
0.2 \mathrm{~mm} / \mathrm{rev}\end{array}$ & $\begin{array}{c}50 \mathrm{~m} / \mathrm{min} \\
0.3 \mathrm{~mm} / \mathrm{rev}\end{array}$ & $\begin{array}{c}60 \mathrm{~m} / \mathrm{min} \\
0.25 \mathrm{~mm} / \mathrm{rev}\end{array}$ & $\begin{array}{c}70 \mathrm{~m} / \mathrm{min} \\
0.2 \mathrm{~mm} / \mathrm{rev}\end{array}$ & $\begin{array}{c}70 \mathrm{~m} / \mathrm{min} \\
0.3 \mathrm{~mm} / \mathrm{rev}\end{array}$ \\
\hline $\begin{array}{c}\text { Valley } \\
\text { height }[\mu \mathrm{m}]\end{array}$ & Emulsion & 272 & 414 & 323 & 253 & 353 \\
\hline $\begin{array}{c}\text { Peak } \\
\text { height }[\mu \mathrm{m}]\end{array}$ & Cryo & 275 & 387 & 350 & 266 & 403 \\
\hline $\begin{array}{c}\text { Peak-peak } \\
\text { distance }[\mu \mathrm{m}]\end{array}$ & Emulsion & 111 & 241 & 143 & 139 & 155 \\
\cline { 2 - 7 } & Cryo & 110 & 206 & 174 & 122 & 210 \\
\hline
\end{tabular}

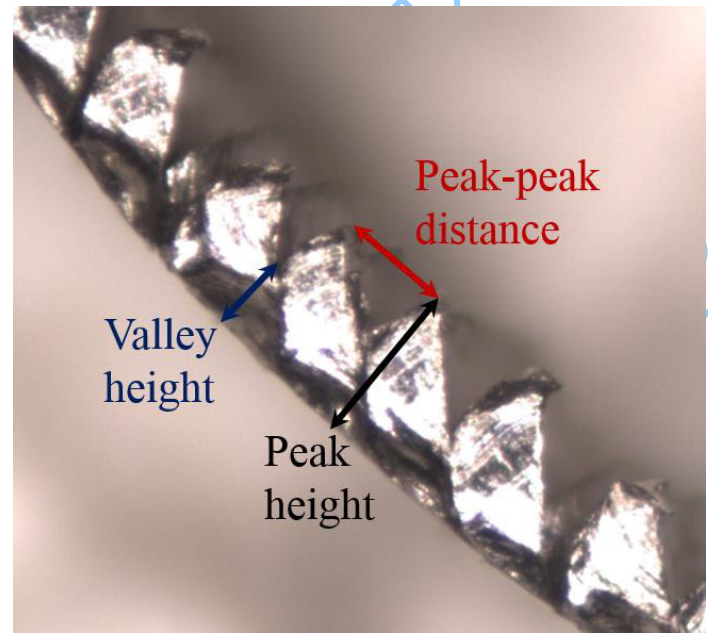

Fig. ${ }^{\circ}$. Chip sample and characteristic dimensions

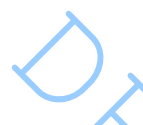

Tribological effects. The calculation of the coefficient of friction is performed using the measured cutting forces through Eq. (1).

$$
\mu=\frac{F_{n} \cdot \cos \left(\gamma_{r}\right)+F_{c} \cdot \operatorname{sen}\left(\gamma_{r}\right)}{F_{c} \cdot \cos \left(\gamma_{r}\right)-F_{n} \cdot \operatorname{sen}\left(\gamma_{r}\right)} .
$$

Where $F_{c}$ is the cutting force, $F_{n}$ is the normal force on the cutting plane defined by feed force $\left(F_{f}\right)$ and radial force $\left(\mathrm{F}_{\mathrm{r}}\right)$ as follows:

$$
F_{n}=\sqrt{F_{f}^{2}+F_{r}^{2}} \text {. }
$$

$\gamma_{\mathrm{r}}$ is the true rake angle and is defined as:

$$
\gamma_{r}=\arcsin \left(\sin ^{2}(\lambda)+\cos ^{2}(\lambda) \sin (\gamma)\right)
$$

The coefficient of friction $\mu$ is influenced by feed rate (p-val. 0.000) and the interaction between feed rate and cutting speed (p-val. 0.010). Cooling method is not significant on friction, hence it can be deduced that cryogenic jet has a double effect, not only heat reduction but also a lubricating action because $\mu$ is equivalent with the traditional emulsion one. $\mu$ decreases as feed rate increases, 
at $0.3 \mathrm{~mm} / \mathrm{rev}$ with a vc of $70 \mathrm{~m} / \mathrm{min}$ the coefficient of friction is higher because the cooling fluids did not reach the tool chip interface in efficient way.

The average surface roughness $(\mathrm{Ra})$ was measured three times during the cutting tests with three replicates each. In every case the Ra was measured when the tool was not significantly worn and resulted influenced only by the feed rate (p-val. 0.000), as expected, and not by the type of cooling. The measured values varies between a minimum of $1.064 \mu \mathrm{m}$ and $2.813 \mu \mathrm{m}$.

Table 6. Mean friction coefficients and surface roughness values

\begin{tabular}{|c|l|r|r|r|r|r|}
\cline { 3 - 8 } \multicolumn{2}{c|}{} & $\begin{array}{c}50 \mathrm{~m} / \mathrm{min} \\
0.2 \mathrm{~mm} / \mathrm{rev}\end{array}$ & $\begin{array}{c}50 \mathrm{~m} / \mathrm{min} \\
0.3 \mathrm{~mm} / \mathrm{rev}\end{array}$ & $\begin{array}{c}60 \mathrm{~m} / \mathrm{min} \\
0.25 \mathrm{~mm} / \mathrm{rev}\end{array}$ & $\begin{array}{c}70 \mathrm{~m} / \mathrm{min} \\
0.2 \mathrm{~mm} / \mathrm{rev}\end{array}$ & $\begin{array}{c}70 \mathrm{~m} / \mathrm{min} \\
0.3 \mathrm{~mm} / \mathrm{rev}\end{array}$ \\
\hline \multirow{3}{*}{$\mu$} & Emul & 0.48 & 0.35 & 0.37 & 0.43 & 0.39 \\
\cline { 2 - 8 } & Cryo & 0.44 & 0.35 & 0.38 & 0.44 & 0.41 \\
\hline \multirow{2}{*}{$\operatorname{Ra}[\mu \mathrm{m}]$} & Emul & 1.123 & 2.434 & 1.784 & 1.247 & 2.436 \\
\cline { 2 - 8 } & Cryo & 1.448 & 2.212 & 1.640 & 1.509 & 2.014 \\
\hline
\end{tabular}

\section{Conclusions and future work}

An experimental study on rough turning of aerospace titanium has been conducted for evaluating the difference (especially in terms of tool life and cutting forces) between conventional emulsion flood cooling and cryogenic cooling. No results were previously available in the literature in the investigated region of cutting parameters. The main findings of the present study are described as follows.

- There is a statistical difference between the two average flank wear progression laws with traditional and cryogenic cooling, with an advantage for cryogenics.

- The main cutting force and the thrust force are not influenced by the cooling method; a slight hardening effect of cryogenic jet can be noticed in radial force which is moderately higher during cryogenic cutting.

- Liquid nitrogen cooling does not affect the mean surface roughness nor chip morphology

- The coefficient of friction is not statistically influenced by the cooling method, hence cryogenic adduction presents heat reduction effect but also a lubrication effect similar to oil-water emulsion

Despite the above mentioned positive results, with the implemented experimental setup, cryogenic cooling helps improving tool life over traditional oil-water emulsion, but especially at lower material removal rates. Unfortunately, in rough turning, high MRR values are required. It must be underlined that these results have been obtained with commercial tools and tool-holders. It would be interesting to verify if, with a tooling system specifically designed and optimized for the injection of the cryogenic jet, the relative advantage of $\mathrm{LN}_{2}$ can be increased also for large MRRvalues. For this purpose, a dedicated tool-holder with $\mathrm{LN}_{2}$ jet nozzles larger and closer to the cutting zone has been designed and built in co-operation with the Italian branch of Sandvik (Fig. 5). The tool-holder also presents a nozzle for an additional and optional adduction of a minimum quantity oil flux. Preliminary tests performed with this new tool-holder showed a substantial improvement in tool life at all the tested cutting conditions; hence, an economic comparison of the machining will be performed. The performance of this new tool-holder will be presented at Esaform 2015. 


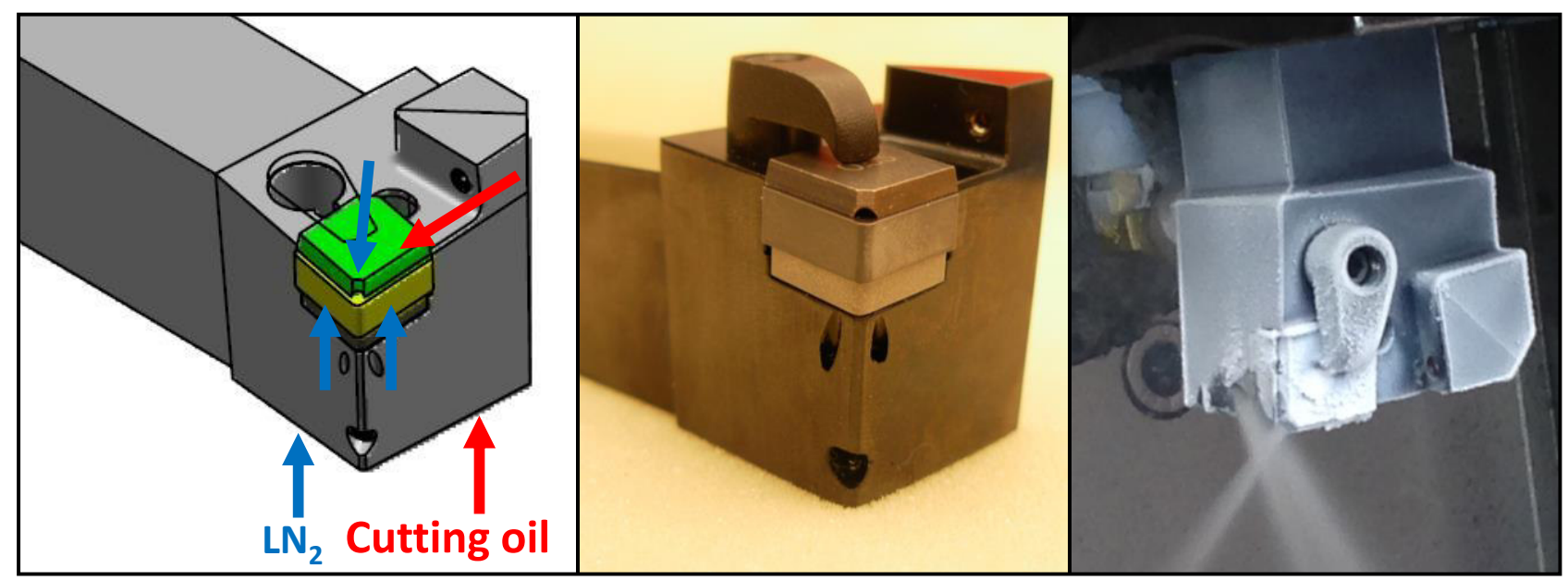

Fig. ${ }^{\circ}$. Drawing and picture of the special purpose tool-holder for cryogenic cooling

\section{Acknowledgments}

The authors wish to gratefully acknowledge the very precious contribution of several engineers and technicians who helped in both the experimental activity and the analysis of the results: Valerio Mussi and Corrado Buroni of MUSP for their valuable help in the conduction of experiments; Antonio Vergari, Fabio Poretti and Andrea Donati of Sandvik for their contribution in designing and manufacturing the new toolholder; Alfredo Malomo and Marco Maffioletti of SIAD for their help in setting up the cryogenic delivery system. This work has been partly funded by the Tecnopolo of Piacenza.

\section{References}

[1] S. Olovsjö, P. Hammersberg, P. Avdovic, J.-E. Ståhl, L. Nyborg, Methodology for evaluating effects of material characteristics on machinability -theory and statistics-based modelling applied on Alloy 718, Int. J. Adv. Manuf. Technol. 59 (2011) 55-66.

[2] E.O. Ezugwu, Z. Wang, Titanium alloys and their machinability-a review, J. Mater. Process. Technol. (1997).

[3] S.K. K Uehara, Chip formation, surface roughness and cutting force in cryogenic machining, Ann. CIRP. 17(1) (1968) 409-416.

[4] Y. Yildiz, M. Nalbant, A review of cryogenic cooling in machining processes, Int. J. Mach. Tools Manuf. 48 (2008) 947-964.

[5] S.Y. Hong, Y. Ding, Cooling approaches and cutting temperatures in cryogenic machining of Ti-6Al-4V, Int. J. Mach. Tools Manuf. 41 (2001) 1417-1437.

[6] M.J. Bermingham, S. Palanisamy, D. Kent, M.S. Dargusch, A comparison of cryogenic and high pressure emulsion cooling technologies on tool life and chip morphology in Ti-6Al-4V cutting, J. Mater. Process. Technol. 212 (2012) 752-765.

[7] M.J. Bermingham, J. Kirsch, S. Sun, S. Palanisamy, M.S. Dargusch, New observations on tool life, cutting forces and chip morphology in cryogenic machining Ti-6Al-4V, Int. J. Mach. Tools Manuf. 51 (2011) 500-511. 
[8] S. Hong, M. Broomer, Economical and ecological cryogenic machining of AISI 304 austenitic stainless steel, Clean Prod. Process. 2 (2000) 0157-0166.

[9] F. Pusavec, J. Kopac, Achieving and implementation of sustainability principles in machining processes, Adv. Prod. Eng. Manag. 4 (2009) 151-160.

[10] K.V.B.S. Kalyan Kumar, S.K. Choudhury, Investigation of tool wear and cutting force in cryogenic machining using design of experiments, J. Mater. Process. Technol. 203 (2008) 95-101.

[11] K.A. Venugopal, S. Paul, A.B. Chattopadhyay, Growth of tool wear in turning of Ti-6Al-4V alloy under cryogenic cooling, Wear. 262 (2007) 1071-1078.

[12] S.Y. Hong, Y. Ding, W. Jeong, Friction and cutting forces in cryogenic machining of Ti6Al-4V, Int. J. Mach. Tools Manuf. 41 (2001) 2271-2285.

[13] V.C. Venkatesh, M.I. Ahmed, A.F. Ismail, Y.A. Abakr, A.K.M.N. Amin, Effectiveness of cryogenic machining with modified tool holder, J. Mater. Process. Technol. 185 (2007) 9196.

[14] K.A. Venugopal, R. Tawade, P.G. Prashanth, S. Paul, A.B. Chattopadhyay, Turning of titanium alloy with $\mathrm{TiB}_{2}$-coated carbides under cryogenic cooling, Proc. Inst. Mech. Eng. Part B J. Eng. Manuf. 217 (2003) 1697-1707.

[15] Z.Y. Wang, K.P. Rajurkar, Cryogenic machining of hard-to-cut materials, Wear. 239 (2000) $168-175$.

[16] M. Dhananchezian, M.P. Kumar, Cryogenic turning of the Ti-6Al-4V alloy with modified cutting tool inserts, Cryogenics (Guildf). 51 (2011) 34-40.

[17] S. Sun, M. Brandt, M.S. Dargusch, Machining Ti-6Al-4V alloy with cryogenic compressed air cooling, Int. J. Mach. Tools Manuf. 50 (2010) 933-942.

[18] S.-C. Jun, Lubrication effect of liquid nitrogen in cryogenic machining friction on the toolchip interface, J. Mech. Sci. Technol. 19 (2005) 936-946.

[19] Y. Ke, H. Dong, G. Liu, M. Zhang, Use of nitrogen gas in high-speed milling of Ti-6Al-4V, Trans. Nonferrous Met. Soc. China. 19 (2009) 530-534.

[20] G. Rotella, O.W. Dillon, D. Umbrello, L. Settineri, I.S. Jawahir, The effects of cooling conditions on surface integrity in machining of Ti6Al4V alloy, Int. J. Adv. Manuf. Technol. (2013).

[21] M.J. Bermingham, S. Palanisamy, M.S. Dargusch, Understanding the tool wear mechanism during thermally assisted machining Ti-6Al-4V, Int. J. Mach. Tools Manuf. 62 (2012) 76-87.

[22] N. Khanna, K.S. Sangwan, Comparative machinability study on Ti54M titanium alloy in different heat treatment conditions, Proc. Inst. Mech. Eng. Part B J. Eng. Manuf. 227 (2012) 96-101.

[23] R.A. Rahman Rashid, S. Sun, G. Wang, M.S. Dargusch, Machinability of a near beta titanium alloy, Proc. Inst. Mech. Eng. Part B J. Eng. Manuf. 225 (2011) 2151-2162. 
[24] D.C. Montgomery, Design and analysis of experiments, 5th ed., New York, 2001.

[25] M. Santochi, F. Giusti, Tecnologia meccanica e studi di fabbricazione, 2000.

[26] S. Hong, I. Markus, W. Jeong, New cooling approach and tool life improvement in cryogenic machining of titanium alloy Ti-6Al-4V, Int. J. Mach. Tools Manuf. 41 (2001) 2245-2260. 